\title{
Evaluación e indicación de las técnicas de difusión-dilución (epsilometría)
}

\author{
EVALUATION AND INDICATIONS FOR DIFFUSION-DILUTION TECHNIQUES \\ (EPSILOMETRY)
}

VJERA TRIANTAFILO V.*

Key words: Epsilometry, Minimal inhibitory concentration.

La epsilometría (E-test $\left.{ }^{\circledR}\right)$ es un método que combina los principios de la difusión en disco y la dilución en agar en el estudio de la susceptibilidad in vitro. Esta metodología puede ser utilizada en una variedad de microorganismos incluyendo fastidiosos y anaerobios.

La epsilometría es muy simple y fácil de usar, y a diferencia de la difusión en disco, entrega un resultado cuantitativo. En términos de costo/beneficios es particularmente útil cuando se requiere testear uno o varios antimicrobianos.

Al igual que la prueba de difusión en disco, este método debe realizarse bajo condiciones rigurosamente controladas y estandarizadas, debiendo aplicarse las recomendaciones publicadas en las últimas guías de la NCCLS. ${ }^{1}$

El epsilómetro PDM se compone de una tira sólida de un material inerte, con una gradiente exponencial continua del antimicrobiano problema en la cara inferior, y una escala de lectura en su cara superior (Figura 1). La gradiente obtenida cubre las concentraciones adecuadas para realizar la CIM del antimicrobiano, lo que corresponde a 20 diluciones dobles seriadas de CIM. Las gamas de concentración corresponden a CIM clínicamente rele- vantes y a puntos seleccionados para la clasificación de grupos de susceptibilidad.

La tira de E-test ${ }^{\circledR}$ se coloca sobre una placa debidamente inoculada, igual que lo requerido en un antibiograma por difusión, y luego del período de incubación requerido, es posible observar una elipse de inhibición cuyo borde intersecta longitudinalmente la tira en una posición donde una concentración específica del antimicrobiano causa la inhibición del crecimiento bacteriano (Figura 2). Este valor, llamado concentración inhibitoria, es una medición directa de la susceptibilidad del microorganismo al fármaco estudiado.

A la fecha, la FDA de E.U.A. tiene aprobada esta metodología en un listado que incluye: miembros de la familia Enterobacteriaceae, Enterococcus spp., Staphylococcus spp., Streptococcus pneumoniae, Streptococcus grupo viridans, Pseudomonas aeruginosa, otras Pseudomonas, Acinetobacter spp. y especies anaerobias.

En la actualidad están disponibles tiras con una variada gama de antimicrobianos pertenecientes a los diferentes grupos: $\beta$ lactámicos, glicopéptidos, aminoglucósidos, macrólidos, quinolonas, lincosamidas, etc.

\footnotetext{
* Laboratorio de Microbiología, Hospital Militar del General Luis Felipe Berieva Aran.
} 


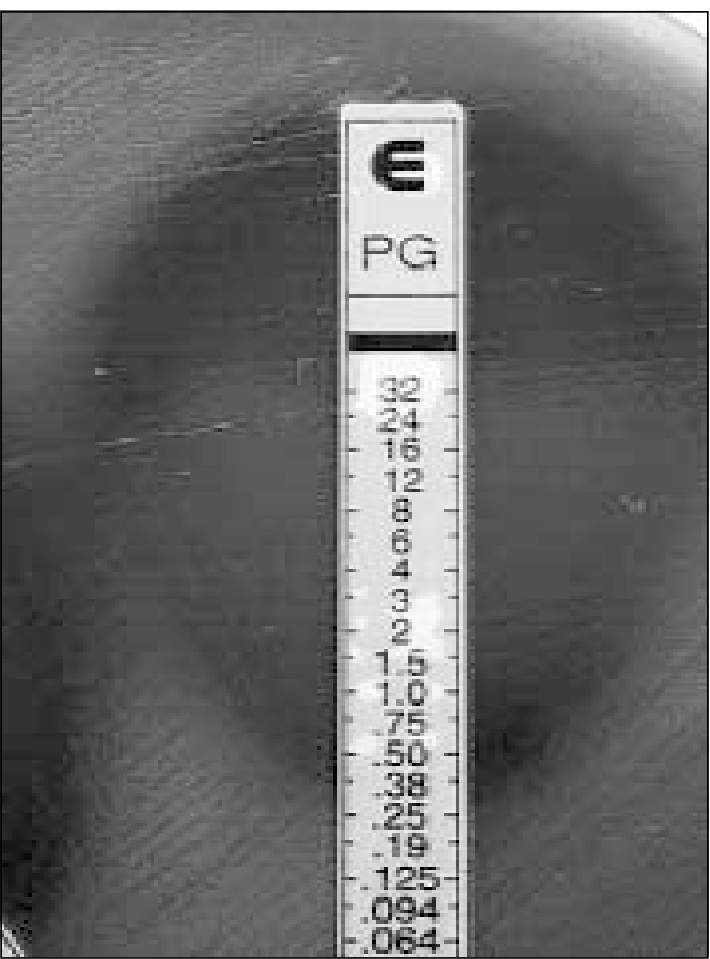

Figura 2. E-test de Streptococcus pneumoniae. Lectura de CIM a penicilina G: $0,25 \mu \mathrm{g} / \mathrm{ml}$.

Figura 1. Tira de E-test®. En su cara superior se aprecia escala de dilución del antimicrobiano impregnado por su cara inferior.

\section{Comparación entre dos métodos de estudio de susceptibilidad in vitro}

\begin{tabular}{lll}
\hline Característica & Difusión/Disco & Epsilometría \\
\hline $\begin{array}{l}\text { Procedimiento } \\
\text { Formato }\end{array}$ & $\begin{array}{l}\text { Lectura demorosa } \\
\text { Cualitativo }\end{array}$ & $\begin{array}{l}\text { CIM directa } \\
\text { Cuantitativo }\end{array}$ \\
antimicrobiana & Inestable & Continua, estable \\
Rango del test & $13-25 \mathrm{~mm}$ diámetro & 15 diluciones de CIM \\
Precisión & $+3 \mathrm{~mm}$ & $+0,5$ diluciones \\
Aplicación & Aerobios de crecimiento & Fastidiosos y no \\
& rápido y algunos fastidiosos & fastidiosos \\
Método & Estricto & Flexible \\
Inóculo & Afecta el diámetro & Efecto mínimo \\
Limitación & Screening & Costo \\
Costo (moneda nacional)* & $\$ 23$ y $\$ 80$ c/disco & $\$ 800-\$ 1.000$ c/tira \\
\hline
\end{tabular}

* Estimación año 2001. 


\section{Indicaciones de la epsilometría en nuestro medio}

- CIM a penicilina y cefotaxima en Streptococcus pneumoniae recuperados de procesos invasores.

- CIM a penicilina y cefotaxima en Streptococcus pneumoniae con lectura $<19 \mathrm{~mm}$ en disco de oxacilina.

- CIM a penicilina en Streptococcus grupo viridans aislados de sitios estériles.

- Evaluación de glicopéptidos (Enterococcus spp, SAMR y S. epidermidis MR recupera- dos de procesos invasores).

- Cepas multiresistentes recuperadas de infecciones invasoras con lecturas borderline en antimicrobianos de elección.

- Estudio de BLEE ( $\beta$ lactamasa de espectro extendido).

\section{BIBLIOGRAFÍA}

1.- National Committee for Clinical Laboratory Standards. Performance standards for antimicrobial susceptibility testing. XII Informational Supplement. M100-S12. Wayne, Pennsylvania, NCCLS, 2002.

Correspondencia a:

Vjera Triantafilo Vladilo

E-mail: vtriantafilo@hosmil.cl 